\title{
Looking Back in Time: Self-Concept Change Affects Visual Perspective in Autobiographical Memory
}

\author{
Lisa K. Libby and Richard P. Eibach \\ Cornell University
}

\begin{abstract}
People who change often report that their old selves seem like "different people." Correlational (Study 1) and experimental (Studies 2 and 3) studies showed that participants tended to use a 3rd-person observer perspective when visualizing memories of actions that conflicted with their current self-concept. A similar pattern emerged when participants imagined performing actions that varied in self-concept compatibility (Study 4). The authors conclude that on-line judgments of an action's self-concept compatibility affect the perspective used for image construction. Study 5 shows applied implications. Use of the 3rd-person perspective when recalling past episodes of overindulgent eating was related to optimism about behaving differently at an upcoming Thanksgiving dinner. The authors discuss the effect of self-concept compatibility on cognitive and emotional reactions to past actions and consider the role of causal attributions in defining the self across time.
\end{abstract}

I am completely different. I've been though a metamorphosis.... I feel as if I woke up one morning to find myself completely different. ... I am just not the same person I was three months ago. I look back and cannot believe that I was her. (Goodman, 1979, p. 69)

Changes in gender role expectations brought on by the feminist movement opened up new possible identities for people in the 1970s and spurred many personal transformations. The quote above is one woman's account of the effect that such a transformation had on her perception of her past self: That past self seems like a different person. This "not me" reaction in response to a discrepant past self occurs as a result of personal transformations in a wide variety of domains. The rhetoric of rebirth in religious conversions suggests such a disconnect between past and present selves, and the practice of adopting a new name on induction into a religion symbolizes the new religious identity. Cancer patients' life narratives reveal the same theme. Many cancer patients refer to a dichotomy between the old self before cancer and the current self after diagnosis. When talking about the time before diagnosis, they often make comments such as "I was really a different kind of person" (Mathieson \& Stam, 1995, p. 299). Part of recovering from an addiction involves adopting a new, nonaddict identity (Biernacki, 1986; Kellogg, 1993; McIntosh \& McKeganey, 2000). As a result of participation in 12-step programs, for example, recovered addicts attest that "We became different people" (Narcotics Anonymous, 1988, p. 11) and "We were reborn" (Alcoholics Anonymous, 1967, p. 104). Such identity transformations seem

We thank Richard Darlington, Ulric Neisser, and Dennis Regan for helpful suggestions concerning this research. We especially thank Thomas Gilovich for advising us, providing numerous invaluable discussions that contributed to the progress of this research, and reviewing the manuscript for us. Lisa K. Libby and Richard P. Eibach collaborated equally in designing and conducting the research reported in this article.

Correspondence concerning this article should be addressed to Lisa K. Libby or Richard P. Eibach, Department of Psychology, Uris Hall, Cornell University, Ithaca, New York 14853. E-mail: LKL3@cornell.edu or RPE1@ cornell.edu to affect the way recovered addicts regard their past behavior: Biernacki (1986) reported that "a common observation made by many [recovered addicts] was that they felt 'funny' talking about their addiction because it "no longer was them"' (p. 177).

These examples imply that the experience of thinking about a past self is influenced by the degree of consistency between that past self's actions and the present self-concept. It is possible to relive a past experience in memory, focusing on reexperiencing a past reaction to the environment. However, when people recall behaviors that are discrepant from the current self, their talk about that past self suggests that instead of reliving a past reaction to the environment, they are focusing on the past self as an object distinct from the present self.

The idea that people can consider the self as either an agent or an object is not new. William James (1890/1950) differentiated between two facets of the self: the $I$, or the "self as knower," and the me, or the "self as known." Cooley (1902), Mead (1934), and Bem (1972) have also proposed theories involving the notion that people can consider themselves from the outside perspective of others. This interest in different standpoints on the self has continued into present theorizing about the self and consciousness (Baars, 1988; Hoyle, Kernis, Leary, \& Baldwin, 1999). Regarding memory in particular, research shows that these different perspectives on the self have literal manifestations in the visual imagery that accompanies autobiographical memory. Nigro and Neisser (1983) found that people can adopt two different visual perspectives when remembering an event: Field memories (i.e., firstperson memories) are visualized as if one is looking through one's own eyes; observer memories (i.e., third-person memories) are visualized as if one is looking at oneself through the eyes of a bystander.

We hypothesized that, like their verbal comments, people's memory images of discrepant past behavior would focus on their past selves. Specifically, people should be more likely to use the third-person memory perspective when recalling actions that are incongruent with their current selves than when recalling actions that are congruent with their current selves. We propose that the critical element in producing disidentification with a past self, and 
visual focus on the past self in particular, is the on-line perception of inconsistency that accompanies the recall of discrepant past behavior. Our prediction and reasoning are consistent not only with anecdotal observations but also with previous research and theory, as we discuss. In light of the relationships among the personal past, present, and future (Johnson \& Sherman, 1990; M. Ross \& Buehler, 2001), understanding the determinants of people's experience of the past could provide insight into the entire range of the temporally extended self.

\section{Self-Schemas and Disidentification With a Past Self}

It may be argued that when people claim that a past self seems like a different person, they are merely using self-presentational linguistic devices. However, we think that the examples we have cited may indeed point to a true phenomenology of disidentification with a discrepant past self. In particular, we propose that this "not me" feeling stems from a mismatch between one's present standards and one's remembered behavior. This mismatch inevitably follows from a defining feature of personal transformation: the adoption of new schemas with which one views the world. Tolstoy (1884/1885) described this aspect of personal change in his book My Religion, which chronicles his religious transformation and details the mindset with which he subsequently came to view the world:

For thirty-five years of my life I was ... a man who believed in nothing. Five years ago faith came to me ... and my whole life underwent a sudden transformation... . What had once appeared to me right now became wrong, and the wrong of the past I beheld as right. ... My life and my desires were completely changed; good and evil interchanged meanings. (p. ix)

We propose that it is this mismatch between present schemas and past behavior that produces the feeling that the past self was a different person.

One reason for this feeling of disidentification stems from the way a change in schema can influence a person's present reaction to remembered events. Interpreting a past situation with new schemas could cause one to react to that past situation differently in the present than one recalls having reacted in the past. William James (1890/1950) argued that being able to reexperience a past reaction is a key element of memories that are considered part of the personal past. To make this point, he gave the example of "dimly recollected experiences" (p. 335), which lack this reliving of past emotion:

We hardly know whether to appropriate [these memories] or to disown them as fancies or things heard or read about and not lived through. Their animal heat has evaporated; the feelings that accompanied them are so lacking in the recall or so different from those that we now enjoy, that no judgment of identity can be decisively cast. (p. 335)

James's (1890/1950) reasoning is consistent with more recent work investigating the link between internal experience and identity. Susan Andersen and Lee Ross (1984) found that people believe that internal aspects (e.g., thoughts and feelings) are better indicators of what someone is really like than are actions.

If one's current emotional and motivational response to a past situation do not map onto one's past emotional reaction and behavior, one may feel as if one has lost touch with that past self and thus sense that a change has occurred. As James (1890/1950) proposed,

If a man wakes up some fine day ... [and] he only recalls the facts of [his biography] in a cold and abstract way as things he is sure once happened; or if . . . his bodily and spiritual habits all change during the night, each organ giving a different tone, and the act of thought becoming aware of itself in a different way; he feels and he says that he is a changed person. (p. 336)

The examples we cited earlier are consistent with James's (1890/1950) idea. When talking about their prechange lives, changed people appear not to focus on their past environments or on reliving their past reactions; changed people seem to focus on their discrepant past selves instead.

\section{Self-Focused Thoughts and Memory Perspective}

Self-focused thoughts are associated with reports of taking the third-person perspective in memory. In their original studies, Nigro and Neisser (1983) specified different types of events for participants to recall; the events that had strong situational inducements to self-awareness (e.g., giving a public talk) were most likely to be recalled from the third-person perspective. In a later study, Rozett (1986) allowed participants to choose the events for which they reported memory perspective; she also asked participants why they had recalled the particular events that they did. Compared with reasons for recalling first-person memories, reasons for recalling third-person memories more often focused on the past self's actions and included more self- than other references. Conversely, first-person memories were more likely than were third-person memories to have been recalled because of the significance of some other object or person (e.g., "I remember my first-grade teacher-she was really friendly and nice. I remember her being really pretty, too"). Reasons for recalling first-person memories also included more other references than self-references. Finally, viewpoint in memory is related to attributions in the same way that actual visual focus is (Storms, 1973). Frank and Gilovich (1989) found that when people's attributions for their own past behavior focused on the self (rather than the situation), they tended to report having third-person (rather than first-person) memories.

Research on individual differences has also shown self-focused thoughts to be related to the prevalence of participants' self-reports of third-person memories (Robinson \& Swanson, 1993; Sugiura, 1996). Recent research on gender differences shows such an effect (Huebner \& Fredrickson, 1999). Women-who typically experience greater physical scrutiny and self-objectification than do men-had more third-person imagery in their autobiographical memories, especially when recalling experiences at university parties, where sexual objectification of women is particularly intense.

\section{The Temporally Extended Self: Past, Present, and Future}

On the surface, the idea that people would be so sensitive to discrepancies in the self may seem peculiar, given the consistency motive of the self (Baumeister, 1998; Greenwald, 1980; Swann, 1985, 1987). However, objective consistency over time does not appear to be a necessary condition for maintaining a coherent identity. In general, people are quite good at creating coherence and meaning where there arguably is none (Gilovich, 1991; L. 
Ross, Lepper, Strack, \& Steinmetz, 1977). Regarding the self in particular, Michael Ross and Cathy McFarland (1988) wrote, "People ... perceiv[e] unity in the face of change by constructing a bridge between the two selves, by explaining how the present state emerged from the earlier one" (p. 300). This is evident in life narratives, which often include turning points and pivotal experiences invoked to account for changes in the life course (McAdams, 1993; McIntosh \& McKeganey, 2000; Pillemer, 1998).

Recent research has even shown that when change in the self implies improvement, discrepancies between the past and present are more self-affirming than is consistency (M. Ross \& Wilson, 2000; Wilson \& Ross, 2001). This is likely related to the role of attribution in defining the temporally extended self. Invoking the notion of an old self when describing past discrepant behavior implies that the past self actively determined that behavior and was not simply forced to behave that way by external forces. However, because the notion of an old self creates a disjunction between the past and present selves, attributing past behavior to this old self means that discrepant actions are not indicative of who the person is today. A dramatic example of this point comes from convicted murderer Steve Roach, who was sentenced to death row and apparently went through an identity change. He dedicated his life to redemption by studying the Bible, getting married, and writing letters to wayward juveniles. Regarding his crime, he asserted, "I know what I did was wrong. I put the blame on myself. But I am not the same person I was then" (quoted in Glasser, 2000, p. 26).

Previously, researchers have documented a tendency to attribute self-discrepant actions to situational causes (Kulik, Sledge, \& Mahler, 1986). The "not me" reaction is similar to this tactic in terms of implications for the present self: In both cases, the behavior in question is not indicative of the current self. However, despite this similarity, the two explanations for discrepant past behavior are fundamentally different when future expectations are considered. Blaming past discrepant behavior on situational forces implies the potential to behave in the same way again, given those circumstances. On the other hand, attributing past discrepant behavior to an old self suggests that if the same circumstances arise again, the new self will act differently. Thus, compared with the inmate who blames his crime on external forces, the inmate who attributes his crime to an old, deviant self probably believes that if put in the same situation again, he would be less likely to behave in an illegal manner. The difference could also be observed in more mundane contexts. Compared with the dieter who blames a past Ben and Jerry's ice cream binge on the presence of the pint in the freezer, the dieter who blames such an incident on an old, overeater self should have more optimism for his or her abilities to restrain ice cream eating if another pint should find its way into the freezer again. Because perceptions of change in the self from past to present have implications for beliefs about the future, the visual perspective that one adopts in memory may be informative not only about one's present state but about one's anticipated future as well.

To test our hypothesis that past actions that are discrepant from the present self-concept tend to be recalled from the third-person perspective, we conducted a series of studies incorporating both correlational and experimental designs. In all of the studies, participants recalled (or imagined) events that were either congruent or incongruent with their present behavioral standards and then reported the visual perspective from which they saw the events in their mind's eye. Our last study suggests the applied implications of our results; in this study we investigate the full range of the temporally extended self by testing the relationship between visual perspective in memories of negative past behavior and participants' expectations for avoiding such behavior in the future. Together, the five studies address discrepancies that may arise out of changes in the self from past to present, across social contexts in the same time frame, and from the present to an imagined future.

\section{Study 1: Remember the Days of the Old School Yard}

\begin{abstract}
While the transition from high school to college may entail no radical break with the past, it has profound and enduring implications for the individual's future. All aspects of a person's life are subject to significant change as a result of becoming a college student... Though less dramatic than a true conversion experience, this example highlights powerful and enduring changes. (McAdam, 1989, p. 745-6)
\end{abstract}

As McAdam explained, young people experience substantial changes in the self on entering college, changes they perceive as significant in determining the future direction of their lives. However, because there is no radical break with the past, there are also likely to be aspects of the self that remain stable over the transition to college. In a straightforward test of our hypothesis, we asked undergraduates to report the perspective of high school memories related to aspects of themselves that had since changed and to do the same for high school memories related to aspects of themselves that had remained stable over that same time period. We also asked participants to rate the extent to which they felt they were reliving each event as they recalled it. We predicted that, compared with memories related to stable aspects of the self-concept, memories related to changed aspects were more likely to be visualized from the third-person perspective and accompanied by less reliving of the past experience.

\section{Method}

Participants. Participants were 12 female Cornell University undergraduates enrolled in psychology or human development classes who received extra credit for their participation.

Materials and procedure. Participants were recruited for a study of self and memory. They arrived at the lab individually or in groups of up to 4, were seated at separate desks, and were given a questionnaire. Instructions on the first page directed participants to nominate the aspect of themselves that had changed the most (or changed the least; order was counterbalanced) since high school. The instructions explained that this could be anything connected to their self-concepts (e.g., religious beliefs, political attitudes, the nature of their relationships). Participants then thought and wrote about this aspect of themselves for $5 \mathrm{~min}$. Next they were asked to retrieve five memories from high school that were related to the aspect of themselves they had just thought and written about. As participants recalled each memory, they wrote down a cue word for the purpose of identifying that memory throughout the questionnaire.

When all participants had recalled five memories, the experimenter introduced the first-person/third-person memory perspective distinction with the following words:

Sometimes we "see" a memory from a first-person perspective. In a first-person memory you see the event from the same visual perspective that you originally did; in other words, in your memory you are looking out at your surroundings through your own eyes. However, at other times we "see" a memory from a third-person perspective. In a third-person memory you see the event from an observer's visual 
perspective; in other words, in your memory you can actually see yourself, as well as your surroundings.

After checking whether participants had any questions about this distinction (none did), the experimenter asked participants to indicate the perspective from which they remembered each of their five memories. Then participants received a booklet that asked three questions about each memory; participants completed all of the questions for one memory before going on to answer those same questions about the next memory. Participants used a scale ranging from 0 (not at all true) to 4 (very true) to answer the first question, "When I remembered this event, it felt as if I were reliving the experience." The next question asked for the approximate date on which the event occurred. Four pairs of contrasting adjectives (emotional-unemotional, happy-sad, pleasant-unpleasant, and hot-cold) were presented in the last question with instructions to circle the one adjective from each pair that best characterized the associations the participant had to the memory. The exact procedure was then repeated for the aspect of the self-concept the participants had not yet addressed (the most or the least changed).

\section{Results and Discussion}

Consistent with our hypothesis, participants reported a thirdperson perspective for a larger proportion of memories related to changed aspects of themselves $(M=0.60, S D=0.27)$ than for memories related to stable aspects of themselves $(M=0.33$, $S D=0.31), t(11)=3.22, p<.008$.

The data also support our intuition that past behavior that is incongruent with the current self is recalled in a more detached way than past behavior that is congruent. On average, when participants remembered events that were related to changed aspects of themselves, they reported less reliving of the past experience $(M=1.78, S D=0.85)$ than they did when remembering events that were related to stable aspects of the self $(M=2.66$, $S D=0.51), t(9)=4.44, p<.002 .^{1}$

A similar effect is evident when we compare memories recalled from the third-person perspective and those recalled from the first-person perspective. Consistent with past research on memory perspective and emotional reactions (Kidorf, 1985; Robinson \& Swanson, 1993), third-person memories $(M=1.70, S D=0.92)$ were accompanied by less reliving of past experience, on average, than were first-person memories $(M=3.05, S D=0.64)$, $t(8)=3.35, p<.01$.

Several researchers have found that memory age is related to memory perspective: Older memories are more likely than are recent memories to be visualized from the third-person perspective (Nigro \& Neisser, 1983; Robinson \& Swanson, 1993; Rozett, 1986). And, in general, one would expect memories to become less vivid over time. Thus, a plausible alternative explanation for our results is that memories related to aspects of the self that have since changed are remembered from the third-person perspective and entail less reliving of past experience simply because they are older memories. However, we found that the mean age of memories related to changed aspects of the self $(M=3.09$ years, $S D=1.07)$ did not differ significantly from that of memories related to stable aspects $(M=3.01$ years, $S D=1.40), t(8)<1$.

Our results are well summarized by the comments one of our participants made when writing about the aspect of herself that had changed the most: "Looking back, I see myself as a very different person. . . . My outlook has changed." Consistent with our hypothesis, we found that subjective perception of change in the self is associated with measurable effects on the imagery and emotional experience that accompany autobiographical remembering. Because of its correlational design, Study 1 provides no empirical evidence about what caused participants to recall changed aspects of themselves from the third-person perspective. Participants were allowed to pick the particular dimensions on which they changed and stayed the same. Therefore, it is possible that participants were recalling different kinds of behaviors when thinking about changed aspects than when thinking about stable aspects. However, we believe the memory perspective effect was due to participants' on-line perceptions of inconsistency between the recalled behaviors and their present self-concepts.

These perceptions of inconsistency arise from a particular defining feature of self-change: change in the schemas people use to interpret the world. When a change in schemas occurs between the time an action is originally performed and the time when it is later recalled, reconstruction of this behavior is likely accompanied by an on-line perception of its inconsistency with the present selfconcept. If on-line perceptions of inconsistency do indeed cause the third-person memory perspective, then we should be able to produce results parallel to those of Study 1 by experimentally manipulating participants' present self-concept to vary its consistency with one particular kind of past behavior. We tested this prediction in Studies 2 and 3.

\section{Study 2: Losing My Religion}

In Study 2, participants were induced to consider themselves as either relatively pro- or antireligious; then all were asked to recall memories of religious behavior. For participants who were induced to feel proreligious, memories of religious actions should be consistent with the current self-concept. In contrast, these same kinds of actions should seem abnormal to participants who were induced to feel antireligious. If on-line perceptions of inconsistency do produce third-person remembering, we should find participants in the antireligious condition to be more likely than those in the proreligious condition to experience the third-person perspective when remembering examples of past religious behavior.

\section{Method}

Participants. Participants were 32 Cornell University undergraduates (20 women, 12 men) enrolled in psychology or human development classes who received extra credit for their participation.

Procedure. Participants were recruited for a study of "religion and your life." On arrival at the lab, each participant was escorted into an individual cubicle and given a questionnaire packet containing the manipulation and dependent measures. The packets differed by condition (proreligious, antireligious). Sixteen copies of each version were randomly ordered in a stack, and participants were assigned to condition as the experimenter handed out the packets in this random order. The experimenter remained unaware of each participant's condition.

The manipulation of pro- or antireligious self-concept (adapted from Andersen, Lazowski, \& Donisi, 1986), required participants to circle yes or no to indicate whether each of 18 statements pertaining to religious thoughts and feelings was currently or had at any time been applicable to them. These statements pertained to participants' attitudes toward the same behaviors in the pro- and antireligious versions but were worded to reflect either a pro- or an antireligious sentiment. In both conditions, all statements

\footnotetext{
${ }^{1}$ Differences in degrees of freedom here and elsewhere are due to missing data.
} 
were preceded by qualifiers such as occasionally or at least sometimes to encourage participants to answer "yes" to most of the statements and thereby adopt the appropriate religious self-perception. (e.g., "At least occasionally, I have felt like devoting time to religious or spiritual activities" vs. "At least occasionally, I have felt like not devoting time to religious or spiritual activities"). When participants finished this part of the questionnaire, the manipulation was complete and they went on to the dependent measure.

The questionnaire explained that participants would be asked to recall some religious events in their lives. The directions specified,

These can be events having to do with your own religion, or with your participation in someone else's. For example, a religious event could be attending a religious ceremony or religious function. It is important that each event be one that you participated in or witnessed first-hand; in addition, try to think of events from the past 5 years or so.

Instructions directed participants to think of one such religious event and to write down a cue word that would identify that memory. The next page introduced the distinction between first- and third-person memories using the same wording as in Study 1. Participants indicated the perspective from which they saw the religious memory they had recalled.

Participants then went on to recall and indicate the perspective for three more religious memories. Following this, participants wrote short descriptions of each of the four events they had recalled. On the next page, entitled "Biographical Information," were demographic questions. Among these questions were two that required participants to assess their religious values: "How religious or spiritual do you consider yourself to be?" and "To what extent do you feel that religion is generally a positive force in society?" Participants answered these questions using scales ranging from -5 (not at all) to +5 (extremely). Andersen et al. (1986) found that when these questions were answered immediately after the manipulation, participants in their proreligious condition made significantly higher ratings than did participants in their antireligious condition. Last, our participants reported the month and year in which each of the four religious events they recalled had originally occurred.

\section{Results and Discussion}

Table 1 displays the number of participants who recalled the first memory from each perspective in the two conditions. As expected, participants who had just been induced to feel antireligious were significantly more likely to recall their first religious memory from a third-person perspective than were participants who were induced to feel proreligious, $\chi^{2}(1, N=32)=7.57, p<$ .006 .

To control for the effect of age of the memory on visual perspective, we conducted a logistic regression predicting memory perspective from condition (pro- or antireligious) and memory age in months. This model predicted the data significantly better than chance alone, $\chi^{2}(1, N=32)=10.63, p<.005$. And, although the effect of memory age was marginally significant, $\chi^{2}(1, N=$ $32)=2.95, p<.09$, the effect of condition was significant, $\chi^{2}(1$,

Table 1

Number of Participants Recalling Memories From Each Visual Perspective in the Two Conditions of Study 2

\begin{tabular}{lcc}
\hline & \multicolumn{3}{c}{ Perspective } \\
\cline { 2 - 3 } Condition & First person & Third person \\
\hline Proreligious & 15 & 1 \\
Antireligious & 8 & 8 \\
\hline
\end{tabular}

$N=32)=4.36, p<.04$. Even when we controlled for the length of time that had passed since the event originally occurred, participants in the antireligious condition were significantly more likely to use the third-person memory perspective than were participants in the proreligious condition.

Finally, our prediction was based on the assumption that participants in both conditions were recalling the same class of behaviors: proreligious behavior. Two research assistants who were unaware of our hypothesis coded participants' descriptions of the recalled behaviors as either pro- or antireligious. Disagreements were settled by a third coder who was also unaware of our hypothesis. Ninety percent of the recalled behaviors were proreligious in tone. ${ }^{2}$ Dropping the few antireligious behaviors only makes the effect stronger: One of 14 participants in the proreligious condition recalled from the third-person perspective, whereas 8 of 14 did so in the antireligious condition, $\chi^{2}(1, N=$ 32) $=8.02, p<.005$.

Overall, these results are consistent with the findings from Study 1 and support our hypothesis that the causal element is the compatibility of past behavior with the present self-concept. Participants were more likely to adopt the third-person perspective when remembering actions that were incongruent with the current self-concept than when remembering actions that were congruent with it.

Figure 1 shows the proportion of participants who adopted the third-person perspective on each of the four religious memories. In the proreligious condition the proportion remained low and relatively stable over the course of the four memories. In the antireligious condition the proportion of participants recalling from the third-person perspective started out high but decreased over the course of the four memories, ending up equal to the proportion in the proreligious condition. ${ }^{3}$ This apparent interaction between condition and memory number can be explained by our hypothesis that on-line judgments about the self-concept compatibility of past behavior influence memory perspective. Fazio, Effrein, and Falender (1981) have shown that recalling examples of traitrelevant behavior has an influence on a person's self-concept. In our experiment, recalling religious memories probably weakened the manipulation in the antireligious condition. If recalling religious memories supports a religious self-concept and if the congruency between self-concept and past action influences memory perspective, then it makes sense that any initial difference in preferred memory perspective between the two experimental conditions would diminish over the course of the four memories. In particular, this diminishing difference between conditions should be due to a decrease in third-person memories for participants in the antireligion condition, compared with a stable, low rate of third-person recall in the proreligious condition.

To test the significance of the apparent interaction between condition and memory number, we created an index variable for

\footnotetext{
${ }^{2}$ Because of an error, 1 participant's packet did not contain the memory description page. Proportion is out of the remaining 31 described behaviors.

${ }^{3}$ Across all four memories, $91 \%$ of the recalled behaviors were judged to be proreligious. There was no significant difference between conditions in the tendency for participants to recall antireligious memories, $\chi^{2}(4, N=$ $31)=2.01, p=.73$. The same trend shows up across the four memories when the few antireligious memories are excluded.
} 


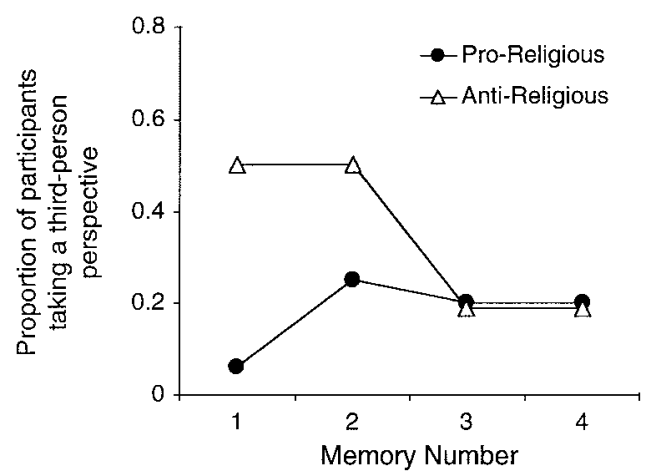

Figure 1. Proportion of participants in each condition taking a thirdperson perspective on each of the four memories in Study 2.

each participant that indicated the tendency to switch perspectives over the course of recalling the four memories. We coded firstperson memories as 1 and third-person memories as -1 for the first two memories, then reversed the coding scheme for the last two memories; we summed these scores for each participant to create the index variable. A participant who did not change memory perspective between the first and second halves of the recall period would get a score of zero; positive scores reflect a tendency to change toward the third-person perspective, and negative scores reflect a tendency to change toward the first-person perspective.

The two conditions differed significantly on this index variable; the mean score in the antireligious condition was significantly lower $(M=-1.25, S D=1.78)$ than that in the proreligious condition $(M=0.25, S D=1.44), t(30)=2.36, p<.013$. Moreover, the score for the antireligious condition differed significantly from zero, $t(15)=2.82, p<.01$, representing a change in preferred perspective (specifically, a change from third to first person) from one half of the recall period to the other. However, the score for the proreligious condition did not differ significantly from zero, $t(15)<1$.

This interpretation of the memory perspective data is also consistent with participants' ratings on the two questions Andersen et al. (1986) had used as a check on their religiosity manipulation. In our study, after the recall period there were no significant differences between pro- and antireligious conditions on either participants' self-ratings of religiousness (proreligious: $M=0.50$, $S D=3.01$; antireligious: $M=0.69, S D=3.26), t(30)<1$, or the degree to which they believed religion is a positive force in society (proreligious: $M=1.38, S D=2.42$; antireligious: $M=1.94$, $S D=2.29), t(30)<1$. Thus, it appears that antireligious participants began to feel relatively more religious as the experiment went on and thus became less likely to recall from the third-person perspective. For proreligious participants, recalling religious memories was consistent with the religious self-schema already induced, and thus these participants remained relatively unlikely to recall from the third-person perspective throughout the recall session.

By manipulating the perceived discrepancy between present self-concept and remembered behavior, we produced the same pattern of results for memory perspective in Study 2 as we observed in Study 1, in which participants themselves nominated the attributes on which they had changed. Notably, in Study 2 participants were all recalling the same kinds of behaviors, but memory perspective varied depending on the consistency of these behaviors with participants' current self-concept. Studies 1 and 2 address perceived change in the self-concept over time. The self-concept can also change across social contexts, though (James, 1890/1950; Markus \& Kunda, 1986; Markus and Wurf, 1987; Mead, 1934). If on-line perceptions of a behavior's self-concept incompatibility cause one to remember that behavior from the third-person perspective, then we should find a tendency to use the third-person memory perspective when a particular self-schema is activated and people recall events related to another self-schema from a contrasting social context. We tested this prediction in Study 3.

\section{Study 3: Double Life}

A man has as many social selves as there are distinct groups of persons about whose opinion he cares. .. . There results what practically is a division of man into several selves; and this may be a discordant splitting, as when one is afraid to let one of his acquaintances know him as he is elsewhere. (James, 1890/1950, p. 294)

Modern empirical research is consistent with the idea that our goals, ideals, and expectancies for our own behavior vary depending on the social setting in which we find ourselves (Markus \& Nurius, 1986; Ogilivie \& Ashmore, 1991). Baldwin (1999) has used the term relational schemas to describe these different representations of the self and behavior in different relationship contexts. Because the behavioral patterns and attributes that define the self under one set of circumstances may conflict with the behaviors and attributes that are salient in another set of circumstances (Fazio et al., 1981), the same behaviors can seem more or less appropriate depending on the relational schema that is activated at the time of processing (Baldwin, 1999). We claim that participants' use of the third-person memory perspective in Studies 1 and 2 was produced by a mismatch between their present self-schemas and their own past behaviors. If this is the case, then we should also find that people tend to use the third-person memory perspective when they recall a behavior that was originally carried out in a different social context than the one that defines their relational schema in the present.

One group that is particularly likely to hold starkly contrasting relational schemas is teenagers. In American culture, at least, when teenagers are with their friends they attempt to assert their selfsufficient identities. However, when in the context of their home and family these same teenagers often seem happy to act just like children. The motivation to keep distinct the separate worlds of home life and peer life appears to be quite strong in children and adolescents (Harris, 1998). According to Baldwin (1999), a distinct discrepancy between relational schemas should cause behaviors and reactions that are customary in one context to appear abnormal in the other. Indeed, Baldwin and Holmes (1987) found that undergraduate women whose relationship with their parents had been primed found a passage depicting promiscuous sexual behavior to be less enjoyable and less exciting than did undergraduate women whose relationship with their peers had been primed (Baldwin \& Holmes, 1987).

In Study 3 we used a technique similar to Baldwin and Holmes's (1987) to manipulate teenage participants' relational schemas: We asked our participants to describe in detail what they were like when they were with their parents or what they were like when with their friends. After this manipulation of presently activated 
relational schemas, we asked the teenagers to recall and report the memory perspective for an event that originally occurred either in the same relational context that they had just described (parents or friends) or in the contrasting relational context. Our prediction was that participants would be more likely to use the third-person perspective when they recalled a memory from a contrasting relational context than when they recalled a memory from the relational context that had just been activated.

\section{Method}

Participants. Participants were 48 high school students enrolled in summer psychology classes at Cornell who received extra credit for their participation.

Overview. In the first part of this study we primed participants' selfschemas in the context of relationships with either their parents or their friends. Immediately afterward, we directed participants to recall an experience they had had either with their parents or with their friends. Thus, the study was a 2 (priming task: parents, friends) $\times 2$ (memory task: parents, friends), fully between-subjects design. Participants arrived at the lab in groups of up to 4; individual participants were randomly assigned to one of the four conditions, with 12 participants in each condition. The experimenter remained unaware of each participant's condition.

Priming task. The participants were seated in cubicles and received an instruction sheet for the first part of the experiment, along with a booklet of blank pages. Depending on condition, the instruction sheet directed participants to spend 5 min thinking and writing about their relationship with their parents or their relationships with their friends. Specifically, the instructions stated,

We'd like you to spend the next five minutes thinking and writing about your relationship with your parents [friends]. As you focus on your relationship, think about the ways that you interact with your parents [friends] and the types of things you say and do when you are with them. Specifically, consider what kind of son/daughter [friend] you are when you are with your parents [friends]. What kind of image do you attempt to project when you are with your parents [friends]? You do not have to write a well-structured essay. Rather, just jot down whatever thoughts come to mind as you reflect on your relationship with your parents [friends].

Participants were given $5 \mathrm{~min}$ to write before the experimenter collected the materials and then distributed the instruction sheets for the second part of the experiment, the memory task.

Memory task. Depending on condition, the instructions directed participants to recall a specific experience that they had had within the past year with either their parents or their friends. Specifically, the instructions read,

We'd like you to recall a specific experience that you had within the past year with your parents [friends]. This memory should be a memory for a specific experience, meaning that the experience occurred at a particular time and place within the past year. Also, this memory should be a memory for an activity that you and your parents [friends] participated in, or experienced, together.

After participants had recalled such an experience, the experimenter introduced the distinction between first- and third-person memories using the same wording as in the two previous studies. Participants indicated the perspective from which they saw their memory.

\section{Results and Discussion}

Table 2 shows the proportion of participants in each condition who recalled the specified memory from the third-person perspective. A chi-square test revealed significant differences between the
Table 2

Proportion of Participants Recalling Memories From the ThirdPerson Perspective in the Four Conditions of Study 3

\begin{tabular}{ccc}
\hline & \multicolumn{2}{c}{ Memory content } \\
\cline { 2 - 3 } Priming condition & Parents & Friends \\
\hline Parents & .17 & .83 \\
Friends & .67 & .42 \\
\hline
\end{tabular}

four conditions in the tendency to have a first- or third-person memory, $\chi^{2}(3, N=48)=12.28, p<.007$. We predicted that the third-person perspective would be relatively more common when the primed context and the memory content were incongruent (i.e., when we primed the self with parents and asked participants to recall an experience with friends, or when we primed the self with friends and asked participants to recall an experience with their parents) than when they were congruent (i.e., when we primed the self with parents and asked participants to recall an experience with their parents, or when we primed the self with friends and asked participants to recall an experience with friends). As can be seen in Table 3 , the results support our hypothesis, $\chi^{2}(1, N=$ $48)=10.10, p<.002$. Seventy-five percent of the memories in which the primed relationship context was incongruent with that in the memory were third-person memories, compared with $29 \%$ of the memories in which the primed relationship context was congruent with that in the memory.

Studies 2 and 3 show that inconsistencies between the present self-concept and recalled behavior produce third-person memories. These results suggest a reason why change in the self is associated with third-person recall of prechange events. The effect is not dependent on the person's having a generalized theory of change in themselves, nor is it due to a gradual morphing of memories from the first- to the third-person perspective over the course of a personal transformation. When a change in the self has occurred, past behavior that is relevant to the changed dimension will be inconsistent with the present self-concept. On-line perceptions of this inconsistency cause this behavior to be reconstructed in memory from the third-person perspective. In the next study we directly test the effect of the perceived normality of engaging in an action on the visual perspective used to construct an image of oneself performing that action.

\section{Study 4: Imagine}

Memory, and all the life of images and words which goes with it, is one with the age old acquisition of the distance senses, and with that development of constructive imagination and constructive thought wherein at length we find the most complete release from the narrowness of presented time and place. (Bartlett, 1932, p. 314)

Memory is a reconstructive process (e.g., Bartlett, 1932; Neisser, 1967; M. Ross, 1989). Thus, as Bartlett noted, remembering and imagining share some fundamental similarities. We propose that the results from our previous studies are due to the effect of perceived self-concept compatibility on the perspective used to construct visual images. If this is the case, then we should find the same effect when participants are asked to construct images of themselves engaging in activities that vary in self-concept compatibility. In Study 4 we asked participants to imagine themselves 
Table 3

Number of Participants Recalling Memories From Each Perspective in Study 3

\begin{tabular}{ccc}
\hline \multirow{2}{*}{$\begin{array}{c}\text { Relationship between } \\
\text { primed self-concept and } \\
\text { memory content }\end{array}$} & First person & Third person \\
\cline { 2 - 3 } & 17 & 7 \\
Congruent & 6 & 18 \\
Incongruent & &
\end{tabular}

performing 10 different activities (e.g., chopping wood, knitting a sweater) and, for each activity, to report the perspective from which they saw the image. Participants also rated the degree of emotion and vividness with which they imagined each of the activities as well as how likely they would be to engage in the activity in the future. We expected that the less likely participants believed they would be ever to engage in an activity, the more likely they would be to use the third-person perspective to imagine it and the less rich the imagined experience would be.

\section{Method}

Participants. Participants were 18 (14 women and 4 men) Cornell University students enrolled in psychology or human development classes who received extra credit for their participation.

Materials and procedure. Participants arrived at the lab individually or in groups of up to 6 . They were seated at separate desks and read an instruction sheet detailing the procedure. This sheet explained that the experimenter would read aloud brief descriptions of 10 hypothetical activities that they were to imagine themselves performing. While listening to each description, they were to close their eyes and place their palms flat on their desks and their feet flat on the floor. When they had the specified image in mind, they were to open their eyes and answer four questions about it in a booklet to be provided. The instructions explained that one of these questions would inquire whether the activity was visualized from the first- or third-person visual perspective. The instructions then introduced the same definitions of first- and third-person perspectives used in previous studies (but substituting image for memory).

After the participants had read the instruction sheets, the experimenter asked whether there was any confusion (no participant reported any) and then distributed the imagination booklets. These had 10 sections, each with the same format, corresponding to the 10 activities to be imagined. In each section participants were to write down the activity they had imagined (to ensure they had followed instructions), circle which perspective (first or third person) they used when imagining the activity, and rate the vividness of the image and intensity of emotion experienced (on scales ranging from $0=$ not vivid at all $[$ not intense at all] to $4=$ extremely vivid [extremely intense]).

The 10 activities were read aloud in the following invariant sequence: rock climbing, chopping wood, knitting a sweater, ballet dancing, playing drums, cheerleading, figure skating, hunting ducks with a rifle, playing a harp, driving a motorcycle. Participants answered the four questions about each activity immediately after imagining it.

After imagining and answering the four questions about the last of the 10 activities, participants answered two additional questions about each activity. First, they indicated how often they had engaged in the activity in the past on a scale ranging from 0 (never) to 6 (many times). Second, they indicated how likely they would be ever to engage in it in the future on a scale ranging from 0 (very unlikely) to 6 (very likely). The latter question was meant to assess participants' judgments of how compatible the action was with their current self-concept.

\section{Results and Discussion}

Visual perspective. Across all 10 activities, we computed the correlation for each participant between visual perspective (coded first person $=1$, third person $=2$ ) and future likelihood. To better meet the assumption of normality required by the $t$ test, here and for the other analyses in this study we performed a Fisher $r$-to- $z$ transformation on these $r$ values before submitting them to a one-group $t$ test against the null hypothesis of zero. As expected, the mean of the transformed correlations between visual perspective and future likelihood was negative $(M=-0.21, S D=0.37)$ and significantly less than zero, $t(18)=2.49, p<.02$. In light of the coding scheme, these results show that the less participants expected ever to engage in the activity, the more likely they were to use the third-person visual perspective to construct an image of themselves engaging in that activity.

Perhaps, however, it is past experience with an activity, not the possibility of ever engaging in it in the future, that accounts for the relationship between perspective and activity type. That is, actions judged to be less likely for the future are probably also less likely to have been performed in the past, and the effect of past experience alone could be responsible for the difference in visual perspective during imagination. To test this explanation, we computed the correlation for each participant between visual perspective and future likelihood, controlling for the frequency of past experience with the activity. The mean of these transformed partial correlations was negative $(M=-0.19, S D=0.36)$ and significantly less than zero, $t(17)=2.22, p<.04$. These results indicate that, independent of past experience, the less an activity fit with participants' on-line judgments about the kinds of activities they could anticipate doing, the more likely they were to use the third-person perspective when constructing an image of themselves doing that activity.

Emotion and vividness. On average, the correlation between participants' ratings of the level of emotion they experienced while imagining each of the 10 activities and the vividness of these images was positive $(M=0.70, S D=0.44)$ and significantly different from zero, $t(17)=6.73, \mathrm{p}<.001$. Therefore, for each activity we summed each participant's emotion and vividness ratings to create a measure of the richness with which the participant imagined performing that action. On average, the transformed correlation between participants' ratings of future likelihood and the richness with which they imagined the action was positive $(M=0.35, S D=0.39)$ and significantly greater than zero, $t(17)=3.69, \mathrm{p}<.002$. To control for the effect of past experience on richness of the imagined event, we recomputed the correlations for each participant between future likelihood and richness, controlling for the frequency of past experience with the activity. The mean of these transformed $r$ values was positive $(M=0.22$, $S D=0.45)$ and marginally different from zero, $t(17)=2.06, p<$ .06 . These results suggest that, independent of past experience, the less participants considered the activity to be something they might do, the less rich was their imagined experience of engaging in that activity.

Consistent with results from Studies 1-3, which involved remembered actions, imagined actions in Study 4 were less richly experienced and more likely to be constructed from the thirdperson perspective when they were less compatible with participants' current self-concept. Together, Studies $1-4$ show that when people think about a behavior that is inconsistent with the current 
self-concept, they tend to see this event from the third-person perspective and tend not to richly experience the visualized action. Using a case in which people are trying to affect a real change in themselves outside the lab, Study 5 investigates the memory perspective effect in the context of the temporally extended self from the past into the future.

\section{Study 5: Over the River and Through the Woods}

A subjective perception of change in the self over time can be defined as a belief that one will behave differently in the present and future than one used to behave in the past. The results from our previous studies suggest that the third-person memory perspective signals a subjective perception of change in the self since the time when the remembered behavior originally occurred. If this is true, then memory perspective should also be associated with optimism about avoiding that past behavior in the future, should one choose to do so.

Study 5 tests this prediction in a domain of attempted selfchange that is familiar to many: diet reform. In the week before Thanksgiving, participants in Study 5 recalled and reported memory perspective for past instances of overindulgent eating. Then they all made predictions about their eating behavior at the same upcoming event: Thanksgiving dinner. Our participants had identified themselves as wanting to avoid overindulgent eating at this event. We predicted that, compared with participants who tended to use the first-person perspective to recall past overindulgent eating episodes, those who tended to use the third-person perspective would be more optimistic about avoiding overindulgent eating at the upcoming Thanksgiving dinner.

\section{Method}

Participants. Participants were 22 (16 women, 6 men) Cornell University undergraduates who wanted to avoid overindulgent eating at the upcoming Thanksgiving dinner. They filled out our questionnaire in exchange for extra credit in their psychology or human development classes.

Materials and procedure. This study was conducted during the week before Thanksgiving 1999 (November 18-22). Participants arrived at the lab in groups of up to 6, were seated at individual desks, and were given a packet that contained all of the instructions and measures. Directions asked participants to recall from the past year "a particular occasion on which you felt like you ate too much, and regretted it" and to write a short description of the event on the three lines provided. Then, after reading the definitions of first- and third-person memory perspectives, participants indicated the memory perspective (first or third person) for the event they had just recalled. On the next two pages, participants used the same procedure for reporting on two more memories from the past year that they recalled in response to the following two prompts, respectively: "a time when you felt like you ate fattening and/or unhealthy food and regretted it" and "a particular occasion on which you felt like you ate what you would define as an excessive amount of food."

At the top of the next page participants indicated whether they would be attending a Thanksgiving dinner (all were) and then went on to answer the rest of the questions, which were about their goals and expectations for their eating behavior at this dinner. Participants answered the same four questions (their desire to avoid the behavior, the effort they would need to do so, the control they would have, and the likelihood of engaging in the behavior) regarding each of two aspects of overindulgent eating: eating too much and eating fatty or unhealthy foods. These questions were together meant to tap optimism for the future associated with perceived change since past overindulgent eating: Participants who believed they had changed should anticipate having more control over their eating behavior while also expecting future overindulgent eating to be less likely and easier to avoid. The questions appeared in the following order.

Participants indicated whether they would ideally like to avoid overeating at the dinner (all did) and then rated on a scale ranging from 0 (no effort at all) to 6 (immense effort) how much effort they thought it would take to do so. Next they indicated whether they would ideally like to avoid eating fattening or unhealthy food at the dinner (all did) and rated on a scale ranging from 0 (no effort at all) to 6 (immense effort) how much effort they thought it would take to do this. The following two questions asked how likely they thought they would be to overeat and how likely they thought they would be to eat more fattening or unhealthy foods than they would ideally like to. Participants answered these questions using scales ranging from 0 (extremely unlikely) to 6 (extremely likely). The last two questions about the upcoming Thanksgiving dinner asked how much control participants thought they would be able to exercise over the amount that they ate and over specifically what they ate at the dinner. For each question, participants answered using a scale ranging from 0 (no control) to 6 (strict control).

\section{Results and Discussion}

Participants' predictions of the effort it would take to avoid each aspect of overindulgent eating (eating too much and eating fatty or unhealthy foods) were significantly correlated $(r=.64, p<.001)$. Predictions about the likelihood of each type of overindulgent eating were also significantly correlated $(r=.63, p<.001)$, as were predictions about control over each type $(r=.57, p<.001)$. Thus, we created composite measures of effort, likelihood, and control by computing the mean of participants' predictions regarding each type of overindulgent eating behavior. As shown in Table 4, composite effort, likelihood, and control measures were correlated with each other in the manner we expected: There was a positive association between effort and likelihood, and each was negatively correlated with predicted control. This pattern of results fits with our expectation that optimism for avoiding overindulgent eating at Thanksgiving would be reflected in low likelihood and effort predictions accompanied by high control predictions. Thus, we reverse-scored the composite effort and composite likelihood measures and added them to the composite control measure to produce an indicator of each participant's perceived optimism for avoiding overindulgent eating at the upcoming Thanksgiving dinner.

We compared the optimism scores of participants who recalled the majority of their three overindulgent-eating memories from the third-person perspective $(n=9)$ with the optimism scores of those who recalled the majority from the first-person perspective $(n=$ 13). As predicted, participants who recalled the majority of their past overindulgent-eating memories from the third-person perspective were significantly more optimistic about their prospects for avoiding such behavior at the upcoming Thanksgiving dinner

Table 4

Correlations Between Predictions Regarding Overindulgent Eating at Thanksgiving Dinner in Study 5

\begin{tabular}{lcc}
\hline & Likelihood & Control \\
\hline Effort needed & $.47^{*}$ & $-.45^{*}$ \\
Likelihood & & $-.61^{* *}$ \\
\hline
\end{tabular}

Note. $\quad N=22$.

$* p<.05 . \quad * * p<.003$. 
$(M=9.34, S D=3.07)$ than were participants who had recalled the majority of their overindulgent-eating memories from the firstperson perspective $(M=6.69, S D=2.80), t(20)=2.14, p<.05$.

A belief that one has changed is a belief that one will act differently from now on than one did in the past. All of the participants in Study 5 wanted to avoid overindulgent eating at the upcoming Thanksgiving dinner. Therefore, all of the participants considered overindulgent eating to be a negative behavior and had motivation to disown their past overindulgent-eating selves. Even so, participants' tendency to recall from the third-person perspective varied depending on their beliefs about whether overindulgent eating was the kind of thing they expected to do again. Therefore, the data from Study 5 provide evidence that converges with the results and interpretation of Study 1 . People who feel as if they have changed tend to use the third-person perspective when recalling prechange behaviors relevant to the changed dimension, and this effect is due to the perceived incompatibility of the recalled behaviors with the current self-concept.

\section{General Discussion}

People tend to focus visual attention on their past self when recalling behaviors that are discrepant from their current self. In Study 1, participants were significantly more likely to use the third-person memory perspective when recalling high school memories related to aspects of themselves that had since changed than when recalling memories related to aspects that had remained stable. Results of Studies 2 and 3 provide empirical evidence that the pattern observed in Study 1 is due to the effect of self-change on people's on-line judgments of the consistency between their past behavior and their present self-concept. Experimentally producing incongruency between present self-concept and remembered behavior caused participants to recall from the third-person perspective. Study 4 strengthens our explanation of the phenomenon observed in Study 1 by establishing a link between on-line judgments about the likelihood of engaging in future actions and the visual perspective participants adopted to construct imaginary images of themselves engaging in those actions.

Additional data show that the recollection or imagining of ego-discrepant activities is associated with less reliving of past experience (Study 1) and less richness of imagined experiences (Study 4) than is the case for ego-congruent activities. Study 5 provides converging evidence that the third-person perspective in memory is an indicator of subjective judgments of change in the self and also suggests the clinical relevance of our research. Participants who tended to recall past overindulgent eating from the third-person perspective also were more optimistic about their ability to avoid such behavior at an upcoming Thanksgiving dinner. Our results have implications for understanding the influence of the self-concept on memory processes; they also speak to the nature of the relationship between the personal past, present, and future.

\section{Influences of the Present Self on Reconstructive Memory}

Ever since Bartlett's (1932) seminal work, psychologists have recognized that memory involves constructive processes that go beyond the mere retrieval of stored information. The message from this research as a whole is that memory is malleable; what one recalls at any given time depends on the influences of present factors on reconstructive processes. For example, stereotypes (Snyder \& Uranowitz, 1978), schemas (Fiske \& Taylor, 1991), scripts (Schank \& Abelson, 1977), expectancies (Loftus \& Palmer, 1974), and implicit theories of change (Conway \& Ross, 1984; M. Ross, 1989) can all influence the contents of people's recollections. Many of these findings also apply to cases of autobiographical recall (Bem \& McConnell, 1970; Conway \& Ross, 1984; Goethals \& Reckman, 1973; Greenwald, 1980; Neisser \& Fivush, 1994; M. Ross, 1989).

Most of the research in the reconstructive tradition has focused primarily on the content of memory. Our findings extend this body of research by demonstrating that the present self can also influence the subjective experience of recalling past events. We have demonstrated that, just like the content of memory, the structure of the visual imagery in memory is malleable and can be influenced by one's present state. When people think about past behaviors that are incompatible with their currently activated self-views, they recall them from a different visual perspective and with less subjective feelings of reliving than when they recall compatible past behaviors.

The results of Studies 2 and 3 are particularly important in demonstrating that the effects we have observed are the result of reconstructive processes that occur at the moment of recall. By experimentally manipulating the congruency between the present self-concept and remembered behavior, we influenced the visual perspective from which people reconstructed their memories. A change in the self causes a person to perceive inconsistency at the moment he or she reconstructs a prechange behavior that is relevant to the changed dimension. This on-line perception of inconsistency causes the third-person memory perspective. Study 4 strengthens this claim. The imagination of events relies heavily on constructive processes; we found that the self-concept compatibility of an action had the same effect on visual perspective in imagination as it did in memory. These subjective aspects of remembering past experiences are important to consider because, as Study 5 suggests, they appear to offer insight not only into a person's present state but into his or her future as well.

\section{Third-Person Perspective, Causal Attribution, and the "Not Me" Phenomenon}

Our studies show a measurable correlate of perceived selfchange that is a literal manifestation of the comments people make when they experience a major change in the self. Changed people say that they feel like their past self was another person; our results suggest that people actually see that past self in memory from the vantage point they would have when looking at another person. In the introduction we pointed out that when people change they adopt a new set of schemas for interpreting the world and thus may have different reactions to past events than they remember having had originally. Study 1 provides data that are consistent with this claim. When recalling events related to changed aspects of themselves, participants reported less reliving of their original experience and were more likely to use the third-person memory perspective. However, one may ask, why would a mismatch between present standards and past behavior cause visual focus on the past self in memory? A possible reason is related to the attributions people are likely to make about a past action depending on its consistency with the current self. 
A mismatch between one's present reaction to a past situation and the way one actually reacted in the past should prompt one to wonder, "Why did I behave that way in the past?" At the same time, the very factors that led to this curiosity should also bias the kind of answer one considers. Because one's present response to the past situation diverges from one's remembered past response, the past situation should not appear to provide sufficient justification for the behavior. Therefore, one would tend to focus on characteristics of the past self to explain the behavior. Research in social judgment has shown a link between attributional explanations and visual focus (Jones \& Nisbett, 1971; McArthur \& Post, 1977; Storms, 1973; Taylor \& Fiske, 1978; Watson, 1982). Moreover, as Frank and Gilovich (1989) found, dispositional attributions for one's own past behavior are associated with use of the third-person memory perspective.

Our explanation of the link between mismatched reactions and focus of causal attribution is analogous to a finding in the realm of social judgment. The false consensus effect (L. Ross, Greene, \& House, 1977) is the tendency to overestimate the commonness of one's own behavioral choices and attitudes. As a result, an observer pays little attention to a target person's personal characteristics when that person acts in accord with the observer's own choice; however, an observer makes overly dispositional attributions about a target person who behaves differently. This research shows that a mismatch between one's own and a target person's reaction to a given situation leads one to focus on characteristics of the target person as responsible for his or her behavior. We propose that when one is thinking about a past situation, a mismatch between one's own present reaction and one's remembered past reaction leads one to focus on characteristics of the past self as responsible for the past reaction.

This discussion of our findings suggests one way the thirdperson perspective could contribute to the distanced "not me" feeling that changed people report when recalling their old behaviors that are inconsistent with their new selves. Simultaneously judging a past behavior to be unnatural and attributing it to characteristics of the past self highlights the contrast between a past self that was responsible for the behavior and the current self that would never dream of acting this way. Under such circumstances, one would not be able to help feeling that the past self was "not me." The result would be a positive feedback process in which sensed discrepancies between present and past selves encourage third-person memories and these third-person memories support dispositional attributions for discrepant past behavior, further enhancing the perceived difference between the present and past selves (Libby, Eibach, \& Gilovich, 2001). As we discuss below, such subjective perceptions of change in the self could be beneficial in the context of attempting to change oneself for the better.

\section{Clinical Implications}

In Study 1, participants were more likely to use the third-person perspective when recalling events related to aspects of themselves that had changed than when recalling events related to aspects of themselves that had remained stable over the same time period. In clinical contexts, people are trying to change themselves so that they no longer engage in the behaviors or emotional reactions that were problematic in the past. In our Study 5 , the more likely participants were to recall past instances of a problematic behavior (overindulgent eating) from the third-person perspective, the more optimistic they were about behaving differently in the near future. This result points to a way our research is relevant to applied clinical contexts.

The tendency to take the third-person perspective when recalling past behaviors may be a valid diagnostic indicator of subjective perceptions of change in the self. Because we recruited participants for Study 5 who specifically wanted to avoid overindulgent eating, all participants in this study considered overindulgent eating to be a negative behavior and all had motivation to think they were presently the kind of people who did not eat overindulgently. Even though this was the case, participants' tendency to recall from the third-person perspective varied depending on their beliefs about whether eating overindulgently was the kind of thing they would in fact do again. A case study of one woman's narratives over the course of psychological treatment (Hyden, 1995) shows a similar link between recovery and objectifying a past problematic self. As the woman began to change and overcome her problem, she shifted from using subject pronouns to using object pronouns when referring to her pretreatment self.

Another issue that is relevant to clinical contexts is the relationship between subjective and more objective changes in the self. Our research focuses on subjective perceptions of change; however, there is reason to believe that these could contribute to actual observable change in the person. Optimism for the future that results from subjective perceptions of change may in fact be beneficial in the quest to achieve actual change. Self-efficacy research (Bandura 1977, 1982, 1997; Hevey, Smith, \& McGee, 1998) has documented the self-fulfilling consequences of expectancies for goal attainment. Other research has shown that fears of relapse can complicate therapy and lead to a number of secondary problems (Fahrion, Walters, Coyne, \& Allen, 1992; King, Nicolini, \& de la Fuente, 1990; Risse, Beitman, \& Brinkley, 1985; Rist \& Davies-Osterkamp, 1977). Thus, the optimism for future improvement that is associated with subjective perceptions of change may contribute to the achievement of objective improvement in the self.

\section{Conclusion}

In essence, all autobiographical remembering involves a split between the present self that is remembering and the past self that is remembered (Reed, 1994). This makes autobiographical memory a convenient context for studying the distinction between the self as agent and the self as object, which has been a topic of theoretical interest among psychologists of the self from William James (1890/1950) to the present (Baars, 1988; Hoyle et al., 1999). It has been suggested that the salience of this distinction between the present self that is remembering and the past self that is remembered is influenced by the magnitude of discrepancy between the two. For example, Prosser (1998) wrote

Autobiography, like the transsexual's first look in the mirror, breaks apart the subject into the self reflected upon, and the self that reflects. . . In transsexual autobiography the split between the "I" of the bios and the "I" of the graph, the past self written and the present self writing, is heightened by the story of sex change... Transsexual history brings into gendered relief the difference present in all autobiography between the subject of the enunciation and the subject enunciating. (p. 102) 
The examples in our introduction are consistent with this idea. Across a variety of domains, people indicate they feel like a different person as a result of major life changes, commenting that the old self is "not me."

Our studies provide empirical evidence for an effect of selfchange on memory. We found that people tend to adopt the third-person perspective in memory when recalling behaviors that are discrepant with their present self. This result suggests that claims of feeling like a different person after life changes are probably not mere self-presentational devices or empty metaphors. They are likely to stem from a real effect of self-congruency on the experience of thinking about a past self. A respondent in Mathieson and Stam's (1995) study of cancer patients' life narratives perhaps captured the effect best when she explained that the life-changing diagnosis of cancer "makes you look at yourself. ... Your perception changes."

Because the memory perspective effect we have documented is a product of present influences on the way people reconstruct the past, the implications of our results extend beyond just an understanding of the way people experience the past. We have demonstrated that the visual perspective people adopt when recalling an event is influenced by on-line judgments about past behavior. Moreover, our data also show that the more likely people are to take the third-person perspective in memory, the more optimistic they are about being able to avoid such behavior in the future. Together, our results suggest that the way people see the past in memory illuminates the relationship they currently perceive between the past and present, with implications for where they anticipate heading in the future.

\section{References}

Alcoholics Anonymous. (1967). As Bill sees it: The AA way of life. Selected writings of A A's co-founder. New York: Alcoholics Anonymous World Services.

Andersen, S. M., Lazowski, L. E., \& Donisi, M. (1986). Salience and self-inference: The role of biased recollections in self-inference processes. Social Cognition, 4, 75-95.

Andersen, S. M., \& Ross, L. (1984). Self-knowledge and social inference: I. The impact of cognitive/affective and behavioral data. Journal of Personality and Social Psychology, 46, 280-293.

Baars, B. J. (1988). A cognitive theory of consciousness. New York: Cambridge University Press.

Baldwin, M. W. (1999). Relational schemas: Research into socialcognitive aspects of interpersonal experience. In D. Cervone \& Y. Shoda (Eds.), The coherence of personality: Social-cognitive bases of consistency, variability, and organization (pp. 127-154). New York: Guilford Press.

Baldwin, M. W., \& Holmes, J. G. (1987). Salient private audiences and awareness of the self. Journal of Personality and Social Psychology, 53, 1087-1098.

Bandura, A. (1977). Self-efficacy: Toward a unifying theory of behavioral change. Psychological Review, 84, 191-215.

Bandura, A. (1982). The self and mechanisms of agency. In J. Suls (Ed.), Psychological perspective on the self (Vol. 1, pp. 3-39). Hillsdale, NJ: Erlbaum.

Bandura, A. (1997). Self-efficacy: The exercise of control. New York: Freeman.

Bartlett, F. C. (1932). Remembering: A study in experimental and social psychology. New York: Cambridge University Press.

Baumeister, R. F. (1998). The self. In D. T. Gilbert \& S. T. Fiske (Eds.), The handbook of social psychology (Vol. 1, pp. 680-740). Boston: McGraw-Hill.
Bem, D. J. (1972). Self-perception theory. In L. Berkowitz (Ed.), Advances in experimental social psychology (Vol. 6, pp. 1-62). New York: Academic Press.

Bem, D. J., \& McConnell, H. K. (1970). Testing the self-perception explanation of dissonance phenomena: On the salience of premanipulated attitudes. Journal of Personality and Social Psychology, 14, 23-31.

Biernacki, P. (1986). Pathways from heroin addiction: Recovery without treatment. Philadelphia: Temple University Press.

Conway, M., \& Ross, M. (1984). Getting what you want by revising what you had. Journal of Personality and Social Psychology, 47, 738-748.

Cooley, C. H. (1902). Human nature and social order. New York: Scribner.

Fahrion, S. L., Walters, E. D., Coyne, L., \& Allen, T. (1992). Alterations in EEG amplitude, personality factors, and brain electrical mapping after alpha-theta brainwave training: A controlled case study of an alcoholic in recovery. Alcoholism: Clinical and Experimental Research, 16, 547552.

Fazio, R. H., Effrein, E. A., \& Falender, V. J. (1981). Self-perceptions following social interaction. Journal of Personality and Social Psychology, 41, 232-242.

Fiske, S. T., \& Taylor, S. E. (1991). Social cognition. New York: McGrawHill.

Frank, M., \& Gilovich, T. (1989). Effect of memory perspective on retrospective causal attributions. Journal of Personality and Social Psychology, 57, 399-403.

Gilovich, T. (1991). How we know what isn't so. New York: The Free Press.

Glasser, J. (2000, January 17). Death be not proud. U. S. News \& World Report, 26-27.

Goethals, G. R., \& Reckman, R. F. (1973). The perception of consistency in attitudes. Journal of Experimental Social Psychology, 9, 491-501.

Goodman, E. (1979). Turning points: How people change, through crisis and commitment. New York: Doubleday.

Greenwald, A. (1980). The totalitarian ego: Fabrication and revision of personal history. American Psychologist, 35, 603-618.

Harris, J. R. (1998). The nurture assumption: Why children turn out the way they do. New York: The Free Press.

Hevey, D., Smith, M., \& McGee, H. M. (1998). Self-efficacy and health behavior: A review. The Irish Journal of Psychology, 19, 248-273.

Hoyle, R. H., Kernis, M. H., Leary, M. R., \& Baldwin, M. W. (1999). Selfhood: Identity, esteem, regulation. Boulder, CO: Westview Press.

Huebner, D. M., \& Fredrickson, B. L. (1999). Gender differences in memory perspectives: Evidence for self-objectification in women. Sex Roles, 41, 459-467.

Hyden, L. (1995). The rhetoric of recovery and change. Culture, Medicine, and Psychiatry, 19, 73 - 90.

James, W. (1950). The principles of psychology (Vol. 1). New York: Dover Publications. (Original work published 1890)

Johnson, M. K., \& Sherman, S. J. (1990). Constructing and reconstructing the past and the future in the present. In R. M. Sorrentino \& E. T. Higgins (Eds.), Handbook of motivation and cognition (Vol. 2, pp. 482-526). New York: Guilford Press.

Jones, E. E., \& Nisbett, R. E. (1971). The actor and the observer: Divergent perceptions of the causes of behavior. Morristown, NJ: General Learning Press.

Kellogg, S. (1993). Identity and recovery. Psychotherapy, 30, 235-244.

Kidorf, M. (1985). Emotion and point of view in personal memories. Unpublished bachelor's thesis, Emory University, Atlanta, GA.

King, D., Nicolini, H., \& de la Fuente, J. R. (1990). Abuse and withdrawal of panic treatment drugs. Psychiatric Annals, 20, 525-528.

Kulik, J. A., Sledge, P., \& Mahler, H. I. M. (1986). Self-confirmatory attribution, egocentrism, and the perpetuation of self-beliefs. Journal of Personality and Social Psychology, 50, 587-594.

Libby, L. K., Eibach, R. P., \& Gilovich, T. (2001). It depends how you look 
at it: Memory perspective influences perceived and actual change in the self. Manuscript in preparation.

Loftus, E. F., \& Palmer, J. C. (1974). Reconstruction of automobile destruction: An example of the interaction between language and memory. Journal of Verbal Learning and Verbal Behaviour, 13, 585-589.

Markus, H., \& Kunda, Z. (1986). Stability and malleability of the selfconcept. Journal of Personality and Social Psychology, 51, 858-866.

Markus, H., \& Nurius, P. (1986). Possible selves. American Psychologist, 41, 954-969.

Markus, H., \& Wurf, E. (1987). The dynamic self-concept: A social psychological perspective. Annual Review of Psychology, 38, 299-337.

Mathieson, C. M., \& Stam, H. J. (1995). Renegotiating identity: Cancer narratives. Sociology of Health \& Illness, 17, 283-306.

McAdam, D. (1989). The biographical consequences of activism. American Sociological Review, 54, 744-760.

McAdams, D. P. (1993). The stories we live by: Personal myths and the making of the self. New York: Morrow.

McArthur, L. Z., \& Post, D. L. (1977). Figural emphasis and person perception. Journal of Experimental Social Psychology, 13, 520-535.

McIntosh, J., \& McKeganey, N. (2000). Addicts' narratives of recovery from drug use: Constructing a non-addict identity. Social Science \& Medicine, 50, 1501-1510.

Mead, G. H. (1934). Mind, self, and society. Chicago: University of Chicago Press.

Narcotics Anonymous. (1988). Narcotics Anonymous (5th ed.). Van Nuys, CA: World Service Office.

Neisser, U. (1967). Cognitive psychology. Englewood Cliffs, NJ: PrenticeHall.

Neisser, U., \& Fivush, R. (Eds.). (1994). The remembering self: Construction and accuracy in the life narrative. New York: Cambridge University Press.

Nigro, G., \& Neisser, U. (1983). Point of view in personal memories. Cognitive Psychology, 15, 467-482.

Ogilivie, D. M., \& Ashmore, R. D. (1991). Self-with-other representations as a unit of analysis in self-concept research. In R. C. Curtis (Ed.), The relational self: Theoretical convergences in psychoanalysis and social psychology (pp. 282-314). New York: Guilford Press.

Pillemer, D. B. (1998). Momentous events, vivid memories: How unforgotten moments help us understand the meaning of our lives. Cambridge, MA: Harvard University Press.

Prosser, J. (1998). Second skins: The body narratives of transsexuality. New York: Columbia University Press.

Reed, E. S. (1994). Perception is to self as memory is to selves. In U. Neisser \& R. Fivush (Eds.) The remembering self: Construction and accuracy in the life narrative (pp. 278-292). New York: Cambridge University Press.

Risse, S. C., Beitman, B. D., \& Brinkley, J. R. (1985). Evaluation of long-term use of antidepressant medication. Hospital and Community Psychiatry, 36, 1215-1216.

Rist, F., \& Davies-Osterkamp, S. (1977). An alcohol-contact program: A training aimed at increasing alcoholics' willpower in tempting situations. Drug and Alcohol Dependence, 2, 163-173.

Robinson, J. A., \& Swanson, K. L. (1993). Field and observer modes of remembering. Memory, 1, 169-184.
Ross, L., Greene, D., \& House, P. (1977). The "false consensus effect": An egocentric bias in social perception and attribution processes. Journal of Experimental Social Psychology, 13, 279-301.

Ross, L., Lepper, M. R., Strack, F., \& Steinmetz, J. (1977). Social explanation and social expectation: Effects of real and hypothetical explanations on subjective likelihood. Journal of Personality and Social Psychology, 35, 817-829.

Ross, M. (1989). Relation of implicit theories to the construction of personal histories. Psychological Review, 96, 341-357.

Ross. M., \& Buehler, R. (2001). Identity through time: Constructing personal pasts and futures. In A. Tesser \& N. Schwartz (Eds.), Blackwell handbook of social psychology: Intraindividual processes (pp. 518544). Oxford, England: Blackwell.

Ross, M., \& McFarland, C. (1988). Constructing the past: Biases in personal memories. In D. Bar-Tal \& A. W. Kruglanski (Eds.), The social psychology of knowledge (pp. 299-314). New York: Cambridge University Press.

Ross, M., \& Wilson, A. E. (2000). Constructing and appraising past selves. In D. L. Schacter \& E. Scarry (Eds.), Memory, brain, and belief (pp. 231-258). Cambridge, MA: Harvard University Press.

Rozett, A. (1986). Determinants of point of view in personal memory. Unpublished bachelor's thesis, Emory University, Atlanta, GA.

Schank, R. C., \& Abelson, R. P. (1977). Scripts, plans, goals, and understanding: An inquiry into human knowledge structures. Hillsdale, NJ: Erlbaum.

Snyder, M., \& Uranowitz, S. W. (1978). Reconstructing the past: Some cognitive consequences of person perception. Journal of Personality and Social Psychology, 36, 941-950.

Storms, M. D. (1973). Videotape and the attribution process: Reversing actors' and observers' points of view. Journal of Personality and Social Psychology, 27, 165-175.

Sugiura, T. (1996). The effects of self-awareness on the internal and external viewpoint for self-imagery. Japanese Journal of Psychology, 66, 418-424.

Swann, W. B. (1985). The self as architect of social reality. In B. R. Schlenker (Ed.), The self and social life (pp. 100-125). New York: McGraw-Hill.

Swann, W. B. (1987). Identity negotiation: Where two roads meet. Journal of Experimental Social Psychology, 53, 1038-1051.

Taylor, S. E., \& Fiske, S. T. (1978). Salience, attention, and attribution: Top of the head phenomenon. In L. Berkowitz (Ed.), Advances in experimental social psychology (Vol. 11, pp. 249-288). New York: Academic Press.

Tolstoy, L. (1885). My religion. (H. Smith, Trans.). New York: Cromwell. (Original work published 1884)

Watson, D. (1982). The actor and the observer: How are their perceptions of causality divergent? Psychological Bulletin, 92, 682-700.

Wilson, A. E., \& Ross, M. (2001). From chump to champ: People's appraisals of their earlier and present selves. Journal of Personality and Social Psychology, 80, 572-584.

Received December 8, 2000

Revision received May 25, 2001

Accepted June 4, 2001 